\title{
O fim da idealização retrógrada da sexualidade é o mágico espiral do apocalipse multissexual eterno ${ }^{1}$
}

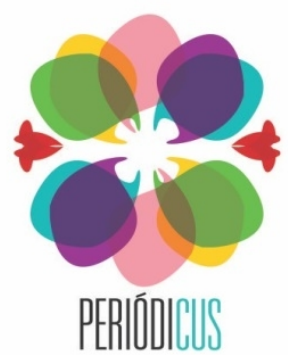

ISSN: 2358-0844

n. 14, v. 2

nov.2020-abr.2021

p. $276-283$
(The end of the retrograde idealization of sexuality is the magical spiral of the eternal multisexual apocalypse)

(El fin de la idealización retrógrada de la sexualidad es el mágico espiral del apocalipsis multisexual eterno)

Hija de Perra ${ }^{2}$

RESUMO: Neste texto, Hija de Perra (1980-2014), performer bizarra, produtora e diretora de espetáculos imundos, aborda e analisa não só o lugar das dissidências de gênero e sexualidade na cultura e no mundo do espetáculo televisivo no Chile, como também da heterossexualidade.

PALAVRAS-CHAVE: Hija de Perra; Gênero e Sexualidade; Chile.

Resumen: En este texto, Hija de Perra (1980-2014), performista bizarra, productora y directora de espectáculos inmundos, aborda y analiza no sólo el lugar de la disidencia de género y sexualidad en la cultura y en los medios televisivos en Chile, sino también el lugar de la heterosexualidad.

Palabras clave: Hija de Perra; Género y sexualidad; Chile.

Abstract: In this text, Hija de Perra (1980-2014), a bizarre performer, producer and director of filthy shows, describe and analyze not only the place of gender and sexuality dissent in the culture and in the television media in Chile, but also the place of heterosexuality.

Keywords: Hija de Perra; Gender and sexuality; Chile.

1 El fin de la idealización retrógrada de la sexualidad es el mágico espiral del apocalipsis multisexual eterno foi publicado originalmente na Revista Punto Género, da Faculdade de Ciências Sociais, da Universidade do Chile, no primeiro semestre de 2012, a quem agradecemos a cessão do texto. A tradução é de Carolina Hartfiel Barroso e Helder Thiago Maia, que sugerem que o texto seja lido irônica e debochadamente, como faria toda hija de perra.

2 Hija de Perra foi uma ativista das dissidências de gênero e sexualidade, performer, modelo, atriz e cantora chilena. Protagonizou os filmes Empaná de pino (2008) e Perdida hija de perra (2010). 
O sexo foi convertido em epicentro de tormentosos e libertadores debates nas ciências sociais e nas ciências duras, pois para os ocidentais sempre esteve rodeado de idealistas fins reprodutivos, recreacionais ou parafílicos que hoje são postos em questionamento.

Além de alguns pioneiros na matéria, estes estudos não têm mais de 60 anos de trajetória. Recentemente, nas décadas de 20 e 30, foram descobertos os hormônios femininos e masculinos, estrógenos e testosterona, por exemplo.

A fisiologia elementar do ato sexual foi analisada durante 12 anos de pesquisa, e os resultados foram recém publicados em 1966. Neste árduo trabalho pioneiro dividiram o ato sexual em 4 etapas: excitação, platô, orgasmo e resolução. Em 1970, o desejo foi agregado como elo perdido dentro da cadeia do exercício amatório.

Estas explorações incitaram reações variadas, e muitas vezes encontradas na época. Em especial - e como sempre - os conservadores levantaram seus braços celibatários e castos tratando de impedir o progresso dos novos saberes sobre este tema tão ardente e fascinante.

Hoje se afirma que o orgasmo é o clímax de nossa experiência sexual, tão breve que se somarmos o tempo de duração de todos os que ocorrem em um ano, uma pessoa com uma vida sexual média acumula apenas 12 minutos.

Como narra um arrepiante artigo da revista Muy Interesante, nos anos de 2003 e 2005, na Holanda, foi realizada uma série de estudos, com tomografia computadorizada, que revelaram o caminho crítico do orgasmo dentro do cérebro.

Nas mulheres descobriu-se que este clímax “desconectava” todo seu cérebro por segundos, quer dizer, concluíram que as fêmeas caem em uma espécie de transe que paralisa sua atividade regular - sobretudo a zona de suas inibições e o juízo pessoal localizados no lóbulo frontal -, o raciocínio paralisa e também os julgamentos sociais localizados no córtex médio frontal. O líder destes estudos, o doutor Gert Hostege, chegou a declarar que "no momento do orgasmo as mulheres não têm emoções”.

Por outro lado, no caso dos homens foi registrada atividade em diferentes partes do cérebro, incluindo a zona de transição mesodiencefálica, na qual estão envolvidos uma grande variedade de mecanismos de recompensa, os mesmos que se ativam quando inalamos cocaína ou injetamos heroína.

A conclusão mais controversa de Holstege: “o orgasmo masculino é uma maneira que a evolução encontrou para reforçar a atividade sexual nos humanos e preservar a espécie”. Assim, enquanto a mulher se desconecta e não tem emoções, o homem é recompensado e preserva a espécie.

Como podemos ver, a natureza converteu o sexo no ato mais reconfortante conhecido 
pelo ser humano, sendo um de seus eixos a gratificação que obtemos na peculiar prática deste, tais como as recompensas fisiológicas e psicológicas que estimulam o cérebro e nos brindam com tranquilidade emocional, satisfação e autoestima, quer dizer, tudo que é necessário para nos sentirmos bem, garantindo de quebra o funcionamento harmônico na sociedade.

Mas para a humanidade ocidental, a sexualidade envolve seguir os estritos códigos e padrões morais inculcados pela cultura cristã e patriarcal. O sexo se converte, desta maneira, em um ato rodeado de condutas e costumes sociais que foram herdados e que permaneceram durante séculos, estigmatizando este belo tema.

Sendo assim, o sexo nos enche de prazer ou de culpa?

No início do século XXI, nos vemos mergulhados em uma realidade de explosão e exploração sexual, nosso ambiente está infestado de sexualidade, ambiente onde vemos como regurgita o vômito sinistro do duplo discurso chileno. Esta moral dupla faz florescer a estupidez humana no mundo de maneira assombrosa.

Um exemplo muito claro de imundice em contingência total e absoluta é o programa de televisão aberta Morandé con Compañía emitido pelo canal ultraconservador: Megavisión.

A partir do suposto objetivo de ser uma fonte de diversão saudável para adultos, são ocultas e evidenciadas as atribuições adquiridas por anos de tradição, assim como a evolução destas acerca do falocentrismo explícito mais puro e folclórico de nosso país.

Vejamos o desfile de personagens horrendos que debocham de nossas almas incautas.

Liderado por um patético e decrépito apresentador que absolutamente carece de beleza televisiva, o que não condiz com o corpo artificial e armado das belas dançarinas que o rodeiam sedentas de abusos, permitindo e aceitando ser vistas como um pedaço de carne penetrável com zero desenvolvimento intelectual e emocional. No programa, elas gozam das paródias onde destacam seus orifícios e redondezas ilusórias, que são consideradas elementos fundamentais na diversão masculina. Durante a semana aparecem ao redor de uma dezena de mulheres de seios plásticos ao lado de outra dezena de humoristas carentes de dietas e academia que surtem uma estética bizarra neste programa, ao que se soma a repentina aparição de algum homenzinho atraente que é convidado surpresa por milagre. Toda essa imundice é o que nos oferece este espetacular programa que nos deleita e nos enche de excitação em cada noite onanista.

Existe também aquela mulher que tanto faz rir nesse espaço peculiar, que é a fêmea grotesca, a velha raivosa, esse herdado e arquétipo exemplo de mulher pós-menopausa que deixou para trás sua aparência fértil e desejável. Ela é quem fomenta o escárnio e a discriminação, destruindo as liberdades emocionais de quem representa.

Por outro lado, nesse cenário fictício existe um cintilante festival de travestismo em 
esplendor, representado pelo precário e ingênuo pensar do macho falocêntrico. Essa combinação é o monstro construído pelo homem que imagina, a partir de seus próprios medos, como é um homossexual. Aqui é onde se materializa o corpo bicha com a chuva de preconceitos, distanciando-se do que é realmente humano. Corpo inventado e montado a partir de uma lógica heteronormativa, o contrário ao sujeito ideal.

Daniela Capona, em um colóquio de teatralidades latino-americanas ocorrido no Campus Oriente da Universidade Católica do Chile, se refere ao personagem bicha que lidera neste espaço televisivo, Tonie Esbelt ${ }^{3}$, dizendo que é basicamente uma das versões do fantasma homossexual da heteronorma, um personagem bastante estúpido, histérico, chamativo, feminilizado e invertido, profundamente acéfalo, sem discurso, um inadequado, um monstro estranho e não natural, um ser que representa o fracasso da moral e um perverso sexual, superficial, sem intelecto, sem espírito, o que não corresponde às dinâmicas estabelecidas como ideais.

Logicamente, é impossível que um ser seja todas essas coisas ao mesmo tempo. Só pode existir na mente de um falocêntrico heteronormado.

Pelo visto, a zombaria encanta a nós chilenos, nos seduz a discriminação e sentir que somos mais que o outro, aparentando uma sexualidade que aprendemos diariamente com o Kike Morandé. Atenção, recordemos que a chilena mais linda do universo se apaixonou por este líder machista, rompendo o lar ideal que prevalece em toda sociedade tradicional e conservadora ${ }^{4}$.

Como estamos tão apaixonados pela discriminação, hoje se questiona abertamente a Lei Antidiscriminação exposta nesta semana no Senado. Evangélicos e católicos estão revoltados porque não poderão seguir tratando como lixo as ruidosas minorias. É óbvio, pois recordemos que Cristo nosso Senhor é loiro e de olhos azuis, em nome de quem foram exorcizados os sodomitas, foram eliminadas as raças não-brancas e foram mantidas atrás das grades as mulheres com inclinações anormais ou libertárias.

Esses líderes ineptos, com um duplo discurso realmente sinistro, muito distantes aos mandamentos e bondades professadas em suas igrejas, mantêm hoje o grito ao céu e enchem de medos suas congregações que tanto os ajudam a aumentar suas enormes contas bancárias.

Recordemos que o Monsenhor Ezzati e o Bispo evangélico Emiliano Soto se manifestaram em oposição descarada a esta lei, de forma pública, proclamando que este projeto faz despertar um desejo em relação a práticas anormais que poderiam, no futuro, ser usadas para relações sexuais com crianças ou outra atração que a pessoa acredite ser conveniente decidir.

3 NT: Para conhecer o personagem Tonie Esbelt, ver, por exemplo, <https://bit.ly/2NrXF3e>. 4 NT: Hija se refere à relação extraconjugal entre Kike Morandé e Cecilia Bolocco. 
Acreditam que todas as pessoas têm direito de ser, sempre e desde que estejam dentro das margens da moral, dos bons costumes e da ordem pública. Eles temem que esta iniciativa legal possa ser utilizada por casais do mesmo sexo para alterar a natureza sexual que regulamentam e regulam instituições como o matrimônio e a família.

Essas pessoas fundamentam seus discursos no medo coletivo, afirmando que se for legalizada a união entre humanos do mesmo sexo, logo outros tipos de atos sexuais serão tolerados, o que levaria ao matrimônio com animais e objetos, logo viria o aborto, então a matança de crianças, o Apocalipse e reinará a catástrofe que conduzirá à destruição do mundo. Diante desta desgraça, nos dizem que somente a luz de Deus pode nos guiar rumo à salvação, procurando ser bons homens e deixando para trás as ações sexuais consideradas monstruosas.

Sabemos, graças ao rádio, em uma reportagem de En la mira, de Chilevisión, e outra sobre pastores evangélicos em Megavisión, que sacerdotes e pastores abusaram de crianças e jovens durante toda sua existência. Em nosso país vemos como o padre Karadima e a madre Paula são ícones da dupla moral que rege a sexualidade chilena, visto que, enquanto proclamam sua pureza religiosa, cometem atos que eles mesmos catalogam como aberrantes.

Por que a Igreja até hoje tem tanta influência em nossa forma de agir e nossas condutas sexuais?

Existe um vazio espiritual, existem pessoas carentes de raciocínio que se deixam levar pela bela história de Adão e Eva e juram enfaticamente que a serpente da árvore é o demônio. Porém, faz tempo que nem todos cremos no coelhinho da Páscoa e na fada dos dentes!

De fato os evangélicos exorcizam coletivamente os homossexuais declarados ou acusados dentro de sua igreja, porque, para os evangélicos, homossexuais levam o demônio em seu interior.

\section{Oh my god!}

Da mesma maneira, existem manifestações abertas contra a união entre homossexuais. Há algum tempo vemos desfilar em plena chuva o Pato Frez e o Gato Juanito, que encabeçaram uma brutal manifestação, colocando como exemplo absurdo a natureza e os animais como forma heteronormativa. Um erro monumental, pois hoje sabemos, graças aos estudos de Joan Roughgarden, em seu livro El arco iris de la evolución, que na natureza existe em abundância a transição de gêneros, por exemplo, mais de oitenta por cento das plantas são hermafroditas, as estrelas do mar também, um terço dos peixes dos recifes de corais também são, muitos peixes nascem fêmeas e depois se transformam em macho e vice-versa, o Rei da selva tem mais relações homossexuais do que heterossexuais e os ratos não têm a concepção humana de família, e se comem e se violam entre irmãos e pais. Na natureza existe a magnitude de diversidade de 
gênero, e para entender isso é preciso somente ver o programa Sexo Salvaje do Animal Planet.

Como Performer Bizarra Multissexual e instrutora de doenças venéreas, constantemente as pessoas se aproximam para me contar sobre seus devires e problemas sexuais. Assim, cheguei a conclusões e informações bárbaras.

Me dei conta de que precisamos de educação sexual, pois toda a informação está baseada nos valores ocidentais que idealizam a sexualidade, normatizando-a e reduzindo-a a objetivos reprodutivos e formativos.

Vejo com meus próprios olhos como as pessoas não desfrutam de suas sexualidades, reprimindo o gozo por conta desses valores debilitados por décadas de isolamento orgástico.

Me encontro em um cenário onde os casais não falam sobre sua sexualidade, que se converte em um verdadeiro tabu que impede que eles se sentem para tomar um chá e se digam com franqueza sobre o que gostam e como gostam.

O homem [chileno] em geral teme sempre, não gosta de mostrar seu pacote nem seus glúteos. Usa as calças bem largas para que não seja possível notar nada, vai à praia com uma verdadeira cobertura e se sente feliz porque essa proteção cobre totalmente suas infelizes saliências masculinas.

Algo que na mulher acontece de forma totalmente contrária. Ela é obrigada a ter suas genitálias notadas, seus seios, sua bunda e tudo muito ajustado em sua vagina, jeans apertadíssimos, sutiãs que elevam o busto, biquínis que são fabricados com dez centímetros de tecido, etc.

Por que estamos acostumados a isso?

Recentemente, nas últimas décadas, podemos apreciar inclusive dentro da cidade o novo homem metrossexual, com o tórax bem visível e calças mais justas que o resto dos homens, notase que vai à academia, mas vai para desenvolver seus braços e peitoral, esquecendo-se completamente das nádegas e pernas, ficando com um corpo bastante estranho. Algo curioso: essa situação não causa grande comoção entre as pessoas.

Atualmente o uso de elementos alheios à natureza está cada vez mais aceito em nossa sociedade, agora os homens não dizem “ah que lindos seios”, senão dizem “uau estão lindos seus implantes de silicone”, algo que vemos diariamente no espetáculo latino-americano quando uma nova vítima do bisturi nos deleita com uma transformação corporal nada natural.

Retornando ao tema da relação dos homens com seu pênis, eles sentem medo por seu membro, insegurança de seu tamanho e grossura, receio do tempo que permanece ereto e de sua ejaculação.

Então, quando fica ereto é preciso atuar rápido, metê-lo velozmente antes que broxe, o 
que se traduz em um ato sexual atordoado e errôneo, onde a mulher não prevalece em nada além da provisão do próprio orifício, causando incômodo e dor.

Por que as mulheres não se atrevem a falar e reclamar dessa atuação?

Muitos homens se queixam que as mulheres são frígidas na cama, claro que sim. Com a rapidez que se requer para sua medrosa ereção é quase impossível excitar-se e dilatar-se em vinte segundos e acabar fascinada com um orgasmo de dois minutos.

Agradeço à evolução e às mulheres valentes que souberam levar uma sexualidade plena e certeira, conseguindo educar a este humano animalesco que precisa muitas vezes de compreensão e entrega.

A muitas mulheres é custoso entregar-se ao ato sexual, pois sempre foram bombardeadas, a vida inteira, com preconceitos e valores errôneos que se transformam e são herdados, criando estruturas, limites e barreiras que impedem que se alcance o prazer.

Nasce a estúpida ideia imbecil de que a vagina é feia, que as mulheres não podem se masturbar, que as mulheres são as que colocam limites, porque se os desafiam poderiam ser taxadas de indecentes e imorais, além do abuso da idealização do hímen como o valorizado objetivo matrimonial em destruí-lo e conceber filhos.

Faz pouco tempo que as mulheres sabem que a vagina é bonita e que, como dizem as avós, uma bela flor que se abre a quem sabe que deve receber dentro dela.

A pornografia tem um papel fundamental na aprendizagem do exercício amatório, lamentavelmente está quase em sua totalidade realizada e dirigida por homens, o que se traduz em crenças muitas vezes alienadas sobre a sexualidade.

Os homens juram que passando a língua como serpente sobre a vagina conseguirão o êxtase feminino, mas não se dão conta que essa flor precisa ser beijada, assim como beijamos amorosamente os lábios da cara em um envolvimento emotivo e idílico.

Homens: descubram as bondades da vagina, sua magia e seus tempos. Já foi o tempo em que a mulher dá a satisfação ao homem, agora é a era em que o homem faz um bom sexo para a mulher.

Nos lugares onde se fomenta a educação sexual, sempre há folhetos para gays, lésbicas e mulheres... e para os homens heterossexuais... por que não há?

Quando perguntei a eles sobre estas circunstâncias, me responderam que eles já sabem o que precisam fazer, diferentemente das mulheres e dos homossexuais.

O homem tão cretino sempre se considerou um líder, mas lamentavelmente sua informação genética prova o contrário disso muitas vezes, por exemplo podemos dizer que não trazem o chip para os afazeres domésticos sem preconceitos e bem realizados. 
Pela lógica, são mais brutos e não pensam muitas vezes nas coisas antes de dizê-las, em geral guardam tudo, as emoções principalmente, e depois os vemos chorando com os filmes ou porque o papai lhe disse "eu te amo”. Bem esquisito tudo isso!

Recomendo fortemente a masturbação individual e coletiva.

Individualmente, graças a ela podemos nos conectar com nosso próprio prazer, reconhecendo nossos genitais, acariciando nosso próprio corpo em um ato de amor próprio e satisfação pessoal.

Coletivamente, aprendemos a reconhecer o genital do outro e lhe proporcionar prazer, desfrutando dos benefícios que vêm depois de uma boa masturbação em conjunto.

Para gozar temos que ser cúmplices, é preciso saber muito bem do que gostamos e como gostamos, distanciando-se daqueles seres que não entendem esta dinâmica.

Nesta sociedade é comumente reconhecido e aceitável a existência de amantes, é lógico e óbvio, se as pessoas temem falar de sexo com seus parceiros e estão insatisfeitas, é natural que busquem com outras pessoas o que não têm, para conseguir a satisfação e o prazer sexual que merecem.

Muitas vezes o amante nos faz manter e resistir a um casamento espantoso e sufocante. Muitas vezes o amante nos faz voltar a valorizar e a nos apaixonar por nossos parceiros.

Entendemos que quando nos apaixonamos completamente com outra pessoa é algo mágico e novo, o descobrir-se e passar momentos inesquecíveis nos faz sentir o redemoinho do deslumbramento e suas borboletas fantásticas do desejo. Ao estar em um casal por muito tempo, isso que era fabuloso e novo se torna ordinário e banal, se transforma em outra linguagem que devemos reencantar para que o amor não se desfaça e nos aborreça.

Como podem ver, já estou cansada dos numerosos estudos e discriminações sobre a homossexualidade e a lesbianidade, creio que é o momento em que devemos estudar aos heterossexuais, que são finalmente os seres que nos classificam e nos trazem ao mundo.

Eu disse, caso encerrado! 